Western University

Scholarship@Western

Department of Economics Research Reports

Economics Working Papers Archive

1978

\title{
A Comparison of Alternative Techniques of Monetary Control under Rational Expectations
}

Michael Parkin

Follow this and additional works at: https://ir.lib.uwo.ca/economicsresrpt

Part of the Economics Commons

Citation of this paper:

Parkin, Michael. "A Comparison of Alternative Techniques of Monetary Control under Rational Expectations." Department of Economics Research Reports, 7822. London, ON: Department of Economics, University of Western Ontario (1978). 
A COMPARISON OF ALTERNATIVE TECHNIQUES OF MONETARY CONTROL UNDER RATIONAL EXPECTATIONS

by

Michael Parkin

June, 1978

Department of Economics Library

FEB 181982

University of Westem Ontario 
A COMPARISON OF ALTERNATIVE TECHNIQUES OF

MONETARY CONTROL UNDER RATIONAL EXPECTATIONS

by

\author{
Michael Parkin \\ Department of Economics \\ University of Western Ontario \\ London, Canada \\ N6A $5 \mathrm{C} 2$
}

This is a revised version of a paper presented at the Money study Group Conference in Memory of Harry G. Johnson, held in Manchester, England, April 10-12, 1978. I am indebted to Robin Bade for help with deriving and checking the results, and to Peter Howitt, Geoffrey Kingston and Clark Leith for valuable comments on an earlier draft. The financial support of the Canada Council is gratefully acknowledged. 


\section{INTRODUCTION}

Within the last two years the central banks of most industrialized countries have adopted some kind of aggregate money supply growth target as a guideline for monetary policy. In the wake of this, the focus of the policy debate has shifted from whether or not the money supply should be controlled to alternative control procedures. The technique of monetary control which is practised by most countries seems to be the following. ${ }^{1}$ First, a money supply growth target is established and set out either as a specific growth rate (for example, in the West German case) or as a range (Canada, the United States, the United Kingdom). Second, the best available forecast is obtained for the growth rate of real output and the price level over the relevant future control period. Third, the best available demand for money function (relevant to the particular aggregate which is the object of control) is then "solved" for that rate of interest which, given the output and price forecast together with the money supply target, will, on the average, achieve that target. Thus, money supply control is achieved by manipulating the interest rate thereby sliding up and down the demand function for money. In the open economy there is the additional monetary policy problem, namely whether to set the foreign exchange rate thereby letting the stock of foreign exchange reserves take the strain of unexpected developments or, of fixing the stock of foreign exchange reserves thereby letting the exchange rate freely fluctuate in response to market forces. The practice most widely used in this regard seems to be that of smoothing out fluctuations in the exchange rate while permitting the stock of foreign exchange reserves to take the strain of random shocks.

Standing in contrast to these widely used procedures is the wellknown monetarist prescription that the money supply should be controlled by 
setting the unborrowed reserve base of the banking system while permitting interest rates to respond to random market forces and, setting the stock of foreign exchange reserves while permitting the exchange rate to reflect market forces.

Until recently, it was widely believed that we had a basis for choosing between these alternative techniques of monetary control provided by Poole's (1972) seminal comparison of an interest rate and money stock rule in a simple static stochastic environment. Boyer (1976) extended Poole's analysis to deal with optimal foreign exchange market intervention thereby making it possible to apply Poole's insights concerning interest rate and money supply comparisons to comparing alternative techniques of control in the open economy. However, there has been a recent revolution in monetary economics which, as far as its policy implications are concerned, appears to undermine all discussions of optimal policy. In particular, Sargent and Wallace (1976) have shown, first, that, provided private agents have the same information as the authorities about the economic environment in which they are operating as well as knowledge of the rules of the game which are being adopted by the authorities, feedback policy rules are no better than non-feedback rules such as, for example, Friedman's $k z$ rule. Second, feedback rules would produce an even worse outcome (measured in terms, for example, of deviations of real output from its full employment level) if those rules were frequently changed so that agents could not predict policy. Third, an interest rate policy (the policy which seems to characterize much of current monetary policymaking) is not even to be regarded as an available option since it gives rise to an indeterminacy of the absolute price level.

This paper accepts the Sargent-Wallace propositions concerning feedback policy rules. It shows however, that there does remain a policy question 
even in a rational expectations world. This question can be posed as the problem of the designing of the automatic shock absorbing capacities of the economy. Shocks which hit the economy from various sources have to influence prices, output, interest rates, the balance of payments, the exchange rate, and the money supply in some degree or other. However, the distribution of the effects of shocks across the different macroeconomic price and quantity variables is not independent of which potential policy instruments are set deterministically and which are allowed to move at random in response to random shocks. The latter, random instruments, are not to be thought of as being manipulated by a feedback rule but as responding automatically to shocks.

The informational assumptions on which the formal analysis of the paper is based are extremely strong and their modification clearly modifies drastically any policy conclusions. These assumptions are that all agents, private and government, have the same information available to them at zero cost. That information includes all the parameters of the relevant economic system as well as knowledge of the true means of all the exogenous variables. Further, the government does not attempt to fool the private agents. All policy strategies are announced and known in advance. ${ }^{2}$ However, information is not complete. The economy is hit by a variety of serially uncorrelated random shocks, the values of which are unknown by both private agents and the authorities until it is too late to do anything about them.

The paper proceeds in the following order. First, in Part II, a stochastic model of a closed economy very similar to that of sargent and Wallace (1975) is set up and used in order to compare two alternative techniques of monetary control. One is the technique which, to the best of my understanding, is that currently employed in a large number of countries, of setting a money 
stock target but of attempting to achieve that target by manipulating interest rates. The other is the more classical technique of controlling the unborrowed monetary base. In Part III, the model is extended to introduce the relevant features of an open economy. In this case, four alternative techniques of control are compared. The first policy considered is one in which the domestic interest rate and foreign exchange rate are set deterministically so as to achieve targets for the money stock and foreign exchange reserves but where the money stock, the base and the stock of reserves are permitted to fluctuate in response to random shocks. This case seems best to capture the policies currently practised in most economies. The second policy considered is one in which the domestic interest rate is fixed thereby letting the unborrowed base respond to market forces but also, the stock of foreign exchange is controlled deterministically, so that the exchange rate is a market-determined variable. This case is analyzed because it is felt that it may characterize the policy adopted in some countries. The third policy considered sets the unborrowed base and the exchange rate permitting the interest rate and stock of exchange reserves to respond to random shocks. The final policy considered is the classical control technique which sets the unborrowed reserve base and the stock of foreign exchange reserves deterministically, leaving the interest rate and foreign exchange rate to be determined by random market forces.

The conclusions which emerge from the analysis are that, given the strong information assumptions made, there is no a priori presumption for any particular technique of monetary control. The analysis throws up the need for an empirical evaluation of the sources of shocks and of certain key macroeconomic parameters in order to best design the automatic shock absorbing capacities of the system. The notion of "best" throws up the 
problem of optimal policy. This paper has nothing to say about such matters. It is a purely positive analysis of the effects of alternative systems' designs on the way in which shocks arising from various sources spread themselves throughout the system to hit the key real and nominal macroeconomic magnitudes.

The most objectionable assumption which permits these conclusions is that all agents (private and government) are able to distinguish transitory from permanent changes in exogenous variables and have knowledge of the "true" model which describes the economy. Although this paper does not address such matters, it may confidently be conjectured that relaxation of these assumptions will point strongly against interest rate and exchange rate control because of potential dynamic instability problems and strongly in favor of setting the monetary base and the stock of exchange reserves permitting interest rates and the exchange rate to absorb some share of the shocks.

II. ALTERNATIVE CONTROL TECHNIQUES IN A CLOSED ECONOMY

The model employed is a conventional descriptive macroeconomic model characterized by an IS-LM system generating aggregate demand and an expectations augmented Phillips type (or, more accurately, Fisher-type) aggregate supply function. In addition, there is a banking sector portfolio behavioral relation specifying the connection between the money supply and the unborrowed monetary base. The model is set out as follows:

$$
\begin{aligned}
& y=\alpha-\beta\left(r-p_{+1}^{e}+p^{e}\right)+u_{1} \\
& m=k y-\eta r+p+u_{2} \\
& m=b+\mu r+u_{3} \\
& y=y^{*}+\frac{1}{\delta}\left(p-p^{e}\right)+u_{4}
\end{aligned}
$$




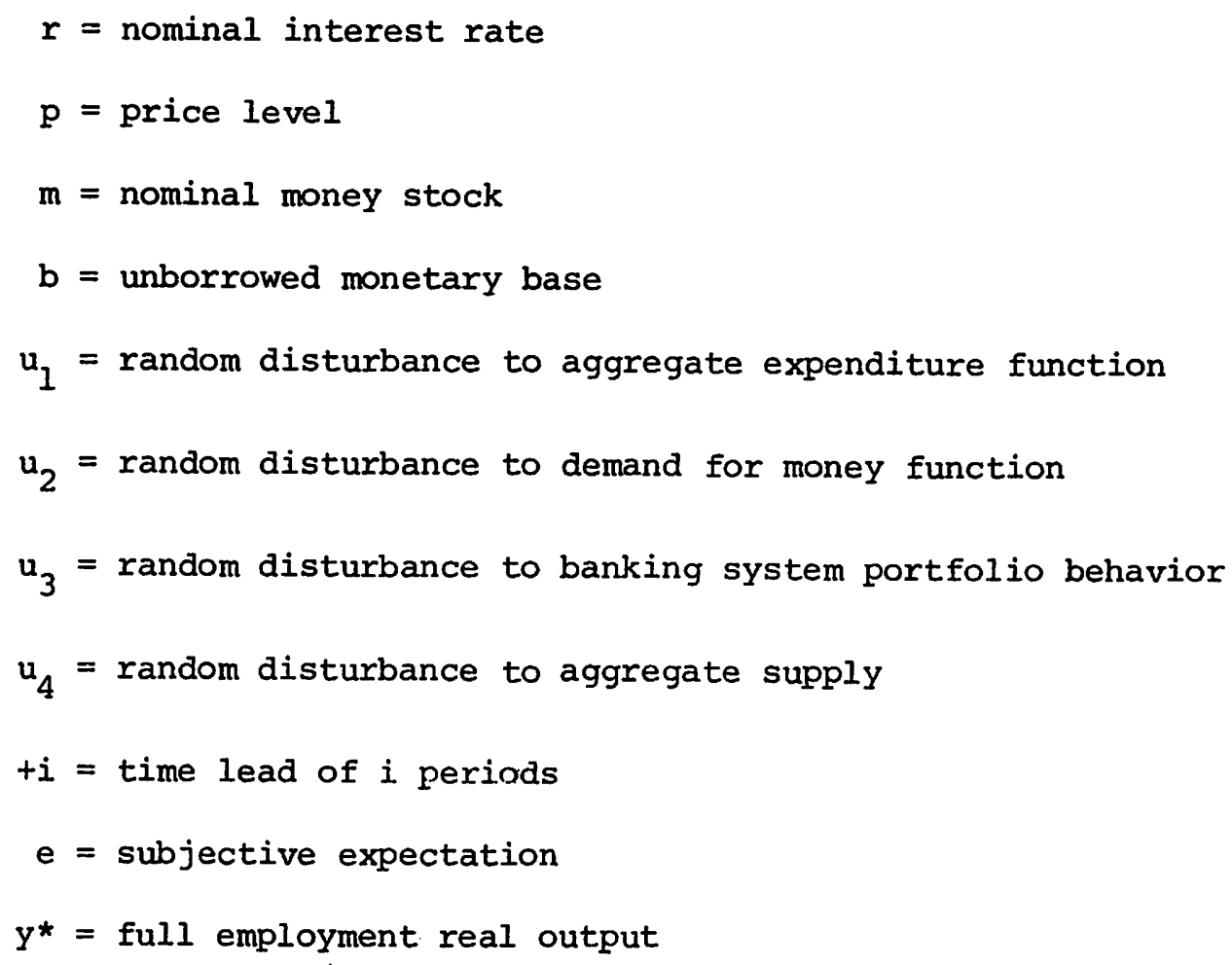

(All variables are expressed in natural logarithms except for the rate of interest which is a proportion.) The six parameters of the model $(\alpha, \beta, \kappa$, $\eta, \mu$, and $\delta$ ) all have ready interpretations. It should be noted that $\alpha$ would contain all the effects of fiscal policy on aggregate demand which are suppressed here purely for the simplification of the exposition. Equation (1) is a conventional stochastic Is curve in which any effects of output on expenditure have already been solved out so that the parameter $\beta$ is the slope of the IS curve (equal to the slope of the aggregate expenditure function divided by one minus the propensity to spend out of income). Equation (2) is a stochastic specification of the demand for money function set equal to the money supply to impose money market equilibrium. Equation (3) describes the relationship between unborrowed banking system reserves, $b$, and the total money stock. This also is specified as a stochastic relation allowing random movements in the banks' demands for unborrowed reserves. Finally, equation (4) is an aggregate supply function which embodies the Fisher (1911, 
Ch. IV) aggregate supply story. This too is specified with an additive stochastic term.

It is worth noting the stochastic features of the world which each of the four random variables $u_{1}, \ldots, u_{4}$ capture. The first, $u_{1}$, is the random disturbances to aggregate investment, consumption and government expenditures. The second, $u_{2}$, represents random fluctuations in private portfolio allocations. The third, $u_{3}$, captures random fluctuations in the portfolio behavior of the banking system. The fourth, $u_{4}$, captures random fluctuations arising from factors of production, technology, or other features of the "state of nature" which affect the available output in the economy. The disturbance term $u_{1}$ is what poole referred to as a real disturbance. It is evident however that in this analysis there are two "real" disturbances, one in the aggregate expenditure function and one in the aggregate supply function $\left(u_{4}\right)$. It is interesting to note that the literature on the macroeconomic aspects of indexation (see in particular, Jo Anna Gray, 1976) treats $u_{4}$ as a real disturbance and $u_{1}$ as part of the "monetary disturbances." The disturbance term $u_{2}$ is what Poole referred to as a monetary disturbance. The disturbance $u_{3}$ is not featured in these previous studies. It is assumed that each of the disturbances $u_{i}(i=1, \ldots, 4)$ are non-autocorrelated, and have zero means.

The four equations set out above, together with the proposition that the subjective expectations $\left(p^{e}\right)$ are the conditional mathematical expectations generated by the model, determine the three endogenous variables, $y, p$, and $m$, together with one of the two potential policy instruments $r$ and $b$. There are thus two alternative policies to be examined. One policy sets the unborrowed reserve base allowing the interest rate along with the other three variables to be determined endogenously and subject to the various random 
shocks captured in the model. The other policy sets the interest rate permitting the unborrowed base to be randomly determined by the system. However, some care is required in specifying the nature of the interest rate control policy. Sargent and wallace (1975) have shown that if the interest rate is set equal to some arbitrary value (say $r^{*}$ ) then the money stock, the price level (and the unborrowed base) are indeterminate. There is no difficulty in verifying that this is a feature of this model. However, the Sargent-Wallace indeterminacy problem would not arise if the monetary authorities' announced target for the money stock, $\mathrm{m}^{\star}$, were believed by all agents and accepted by them as the expected value of $\mathrm{m}$. In other words, there is no indeterminacy if the monetary authority tells private agents what the value of $\mathrm{m}$ will be on the average and if private agents believe the authorities. In this event, the expected and actual price levels will be determinate even though the actual (random) value of the money stock is the outcome of a process in which the interest rate is set deterministically. The alternative policy is one which sets the base deterministically to achieve an expected money stock of $\mathrm{m}^{*}$ while permitting the interest rate level and actual value of the money stock to respond to the system's noise. These two alternative policies are now compared.

\section{(a) Deterministic Interest Rate Random Unborrowed Base Policy}

All agents (the authorities and private agents) do their economic forecasting by taking the expected value of the basic system (1) - (4). From this exercise, it is clear that the expectation of the aggregate supply function yields the proposition that the expectation of $y$ is equal to $y^{*}$. Using this fact, and taking expectations of equations (1), (2) and (3), it is clear that 


$$
\begin{aligned}
& y^{*}=\alpha-\beta\left(r-p_{+1}^{e}+p^{e}\right) \\
& m^{*}=k y^{*}-n r+p^{e} \\
& m^{*}=b^{e}+\mu r
\end{aligned}
$$

Here, $m^{*}$ is the exogenously announced target value for the money stock, and the value which agents believe will, on the average, be achieved. The expected value of the monetary base, $b^{e}$, is determined recursively from equation (7). The interest rate appears in these three equations without an expectational superscript because the process whereby the interest rate is set involves the solution of these equations. Indeed, equations (5) and (6) can be thought of as the forecasting model used by the authorities for determining what interest rate may be expected to deliver the pre-specified monetary target. ${ }^{3}$ Equations (5) and (6) then are solved simultaneously for the value of the interest rate to be set deterministically and for the expected price level. The latter will be given by:

$$
p^{e}=\sum_{i=0}^{\infty}\left(\frac{\eta}{1+\eta}\right)^{i}\left(\frac{\alpha}{\beta}-\left(\frac{I}{\beta}+\frac{\kappa}{\eta}\right) y_{+i}^{*}+\frac{I}{n} m_{+i}^{*}\right)
$$

The interest rate will be set at a value equal to:

$$
r=\frac{1}{n}\left(\kappa y^{*}-m^{*}+p^{e}\right)
$$

where $\mathrm{p}^{\mathrm{e}}$ is the value determined by equation (8). It is clear that, in conformity with the standard rational expectations result, the expected price level depends on the whole future path of the money stock as well as real output. However the weights applied to future values diminish geometrically. Notice that it is necessary for $\mathrm{m}^{*}$ to be announced and believed, into the infinite future. 
To see how the actual values of real output, the price level, the money stock and the unborrowed base are determined, equations (8) and (9) are used to eliminate the interest rate and the expected price level from equations (1) - (4) which are then solved for the four endogenous variables. It is more illuminating however to focus on the deviations of output from its full employment level, $\mathrm{y}-\mathrm{y}^{*}$; of the price level from its expected level, $p-p^{e}$; of the money stock from its target value, $m-m$ * and finally of the unborrowed base from its expected level, $b-b^{e}$. These are obtained by using equation (4) and also by subtracting equation (5) from equation (1), equation (6) from equation (2), and equation (7) from equation (3). Performing these operations and eliminating unexpected inflation from equation (4) yields the following propositions:

$$
\begin{aligned}
& \left(y-y^{*}\right)=u_{1} \\
& \left(p-p^{e}\right)=\delta\left(u_{1}-u_{4}\right) \\
& \left(m-m^{*}\right)=(k+\delta) u_{1}+u_{2}-\delta u_{4} \\
& \left(b-b^{e}\right)=(k+\delta) u_{1}+u_{2}-u_{3}-\delta u_{4}
\end{aligned}
$$

These propositions are extremely simple and straightforward to understand. Deviations of real output from full employment are exactly equal to the random disturbance in the Is curve. The reason for this is best seen by considering the aggregate demand/aggregate supply relations in $p, y$ space (Figure 1). Because of the interest rate policy, the money stock is determined randomly and the aggregate demand function ( $A D$ ) (in $p, y$ space) is vertical (marked $\mathrm{AD}(r=\bar{r})$. Thus the level of real output depends on the position of that vertical line which in turn fluctuates around $y^{*}$ as given by $u_{1}$. This is illustrated in Figure $l$ as the dashed line at $y^{*}+u_{1}$ which is 
drawn for a specific, but arbitrary, positive value of $u_{1}$. Unlike the Sargent-Wallace case, there is no indeterminacy of the price level even though the aggregate demand function is vertical because the aggregate supply function (AS) has a finite slope and a determinate intercept. Its slope of course is simply given by $1 / \delta$ and the intercept determined by the fact that $A S$ cuts the $y^{*}$ line at $p^{e}$ as given in equation (8) above. The price level deviates from its expected level by a combination of two disturbances, that on the Is curve feeding through to the $\mathrm{AD}$ curve and that on the AS curve, $u_{4}$. The weight attaching to both of these disturbance terms is $\delta$. The diagram illustrates the determination of $p\left(=p_{0}\right)$ as deviating from $p^{e}$ as a result of the two shocks, $u_{1}$ and $u_{4}$, the former leading to $a$ movement along the AS curve and the latter to a shift in AS. The money stock will deviate from its target level as a result of three shocks, the aggregate demand shock coming from the IS curve, the aggregate supply shock as well as the demand for money function shock. These are set out in equation (12). The aggregate demand shock $u_{1}$ is multiplied by the income elasticity of the demand for money $K$. The price level shock comes through onto the money stock in its entirety reflecting the fact that the demand for nominal balances is degree one homogeneous in the absolute price level. Also the money demand function shock itself has to be added to these shocks. Finally, the deviations of the unborrowed base from its expected level reflect all the shocks to the aggregate money stock plus the addition of the disturbances arising from random movements in bank portfolio behavior.

Thus, given this technique of monetary control, the four random disturbances distribute themselves throughout the economy in a very precise way. The only shock which affects real output is the Is curve disturbance. Bank 


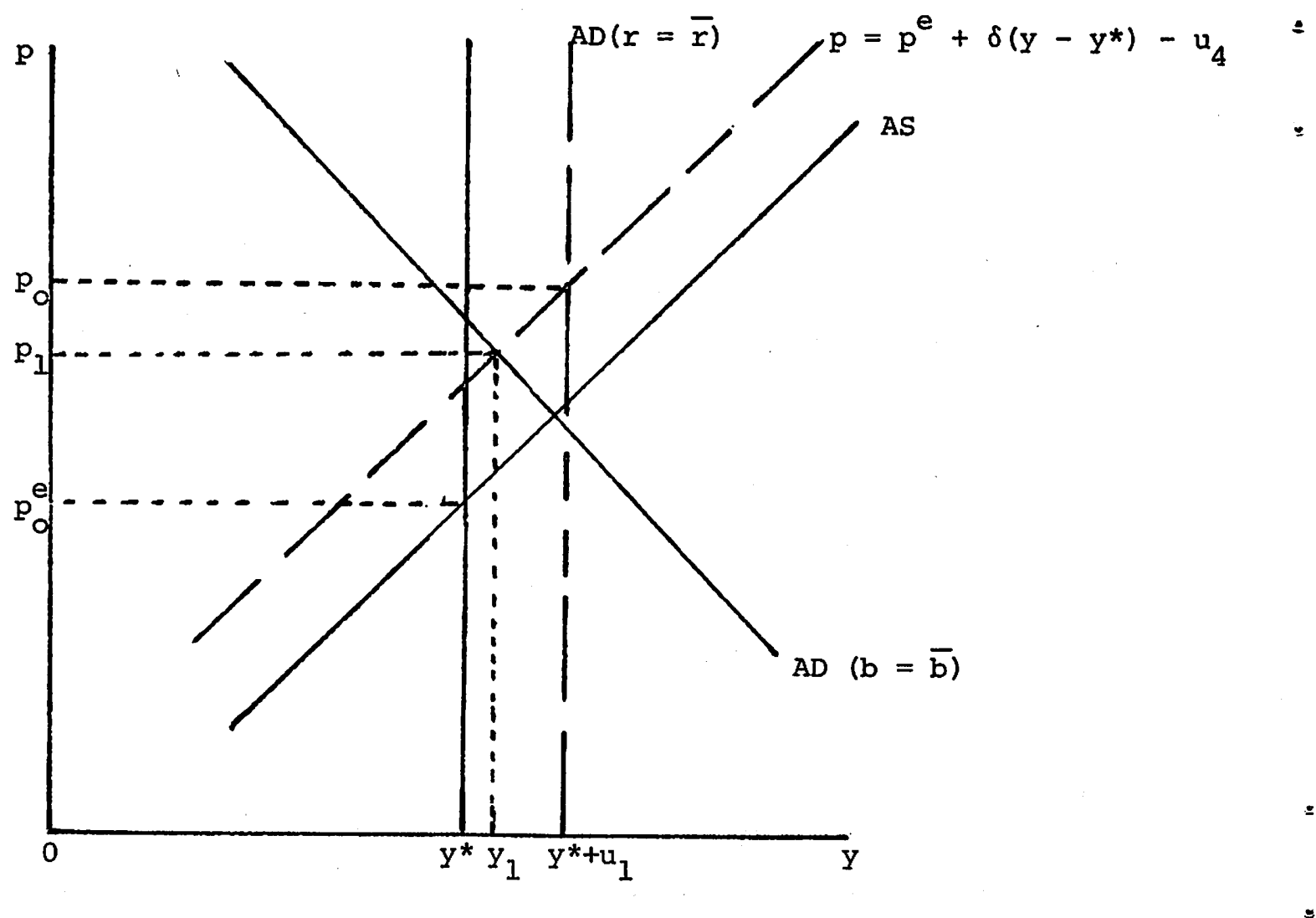

FIGURE 1 
portfolio behavior, demand for money disturbances as well as aggregate supply disturbances are not allowed to feed through to affect the level of real output with an interest rate procedure for achieving the money stock target. The price level itself is influenced only by aggregate expenditure and aggregate supply curve shocks. It is in the money market where the shocks are being concentrated with demand for money as well as IS and aggregate supply shocks affecting the aggregate money stock and all the shocks coming through to affect the unborrowed component of the base, making that the most noisy variable in the system. This control technique will now be compared with one which sets the monetary base exogenously and deterministically in order to achieve a target and expected value of the money stock equal to $\mathrm{m}^{*}$.

\section{(b) Exogenous and Deterministic Unborrowed Base} to Achieve Money Supply Target

All economic agents (private and government) know the policy environment in which they are operating and perform their forecasting exercise by taking expectations of the basic system (1) - (4). This gives them expectations (forecasts) of the price level, the interest rate, and real output. Again, noting that equation (4) implies that expected output equals $Y^{*}$, the forecasting equations become:

$$
\begin{aligned}
& y^{*}=\alpha-\beta\left(r^{e}-p_{+1}^{e}+p^{e}\right) \\
& m^{*}=k y^{*}-\eta r^{e}+p^{e} \\
& m^{*}=b+\mu r^{e}
\end{aligned}
$$

These equations are solved by the authorities in order to make their unborrowed reserve base policy choice and also by private agents to make and implement their goods and money market supply and demand decisions. The 
solution for the expected price level emerging from this model is exactly the same as that contained in equation (8) above. The solution for the expected rate of interest is the same as that given in (9) above except that now it is the expected interest rate not the actual interest rate that equation (9) determines.

To examine the actual behavior of the interest rate together with that of output, prices and the money stock, it is convenient to consider the deviations of these four variables from their target or expected values as before. Subtracting (14) from (1), (15) from (2), (16) from (3) and also using equation (4), the basic system describing the deviations of each variable from its expected or target value is as follows:

$$
\begin{aligned}
& y-y^{*}=-\beta\left(r-r^{e}\right)+u_{1} \\
& m-m^{*}=\kappa\left(y-y^{*}\right)-\eta\left(r-r^{e}\right)+\left(p-p^{e}\right)+u_{2} \\
& m-m^{*}=\mu\left(r-r^{e}\right)+u_{3} \\
& y-y^{*}=\frac{1}{\delta}\left(p-p^{e}\right)+u_{4}
\end{aligned}
$$

Writing this system in matrix form gives:

$$
\left[\begin{array}{rrrr}
1 & 0 & 0 & \beta \\
\kappa & 1 & -1 & -n \\
\delta & -1 & 0 & 0 \\
0 & 0 & 1 & -\mu
\end{array}\right]\left[\begin{array}{l}
y-y^{*} \\
p-p^{e} \\
m-m^{*} \\
r-r^{e}
\end{array}\right]=\left[\begin{array}{c}
u_{1} \\
-u_{2} \\
\delta u_{4} \\
u_{3}
\end{array}\right]
$$

and, inverting the matrix on the left-hand side of (20) gives the effects of the disturbance terms on the actual values of the endogenous variables as: 


$$
\left[\begin{array}{l}
y-y^{*} \\
p-p^{e} \\
m-m^{*} \\
r-r^{e}
\end{array}\right]=\frac{1}{D}\left[\begin{array}{cccc}
\mu+\eta & \beta & \beta & \beta \\
\delta(\mu+\eta) & \delta \beta & -(\beta \kappa+\mu+\eta) & \delta \beta \\
\mu(\kappa+\delta) & -\mu & -\mu & \beta(\kappa+\delta)+\eta \\
(\kappa+\delta) & -1 & -1 & -1
\end{array}\right]\left[\begin{array}{c}
u_{1} \\
-u_{2} \\
\delta u_{4} \\
u_{3}
\end{array}\right]
$$

where $D=\beta(K+\delta)+\mu+\eta$

It is immediately evident that the disturbances $u_{1}, \ldots, u_{4}$ are now distributed throughout the economy in a very different way from what they were in the previous policy regime. First it is noteworthy that all the disturbances affect all the variables, with the exception of the monetary base which is now set deterministically. It is also noteworthy however that there is no unambiguous worsening of the variability of any of the variables (with the exception of the interest rate which in the previous policy was deterministic and now depends on all four of the random disturbances to the system). Perhaps the most interesting variables are real output fluctuations and unanticipated price level movements. It is clear in this case that, in general, the effects of the disturbances $u_{1}$ and $u_{4}$ have been damped in their influence on output and unexpected price level movements. This arises because the $A D$ function is now downward sloping, so that a given horizontal shift (in py space) gives a smaller rise in both $y$ and $p$ than in the vertical $A D$ curve case. This is illustrated by comparing the two AD curves in Figure 1. Further, because of the downward slope on $A D$, a shift in the AS curve has a smaller effect on prices, though, of course, a non-zero effect on output. It is also clear however that random fluctuations in the demand for money function $\left(u_{2}\right)$ as well as in bank portfolio allocations $\left(u_{3}\right)$ which, under the interest rate rule had no effect on aggregate output and unanticipated price movements now do have an influence on those variables. 
In other words, the $A D$ curve shifts as a result of $u_{2}$ and $u_{3}$ shocks. A full and detailed comparison of the system depicted in (21) with equations (10) - (13), which describe the effects of the interest rate rule, would be lengthy and tedious. However some insights and limited comparisons can be performed by considering a few special cases.

First it is worth noting that if $\beta \rightarrow 0$, that is, if the Is curve tends to display a zero interest elasticity then system (21) becomes:

$$
\left[\begin{array}{l}
y-y^{*} \\
p-p^{e} \\
m-m^{*} \\
x-r^{e}
\end{array}\right]=\left[\begin{array}{cccc}
1 & 0 & 0 & 0 \\
\delta & 0 & -1 & 0 \\
\frac{\mu(k+\delta)}{\mu+\eta} & \frac{-\mu}{\mu+\eta} & \frac{-\mu}{\mu+\eta} & \frac{\eta}{\mu+\eta} \\
\frac{k+\delta}{\mu+n} & \frac{-1}{\mu+\eta} & \frac{-1}{\mu+\eta} & \frac{-1}{\mu+\eta}
\end{array}\right]\left[\begin{array}{c}
u_{1} \\
-u_{2} \\
\delta u_{4} \\
u_{3}
\end{array}\right]
$$

It is clear that in this case deviations of output from its full employment level as well as unanticipated price movements are the same as they would be with an interest rate control rule. The key difference in this case is that both the money supply and the interest rate display all the shocks in the system whereas under an interest rate control regime the banking sector portfolio disturbance does not affect the money stock and the interest rate is deterministic with the effects of the shocks being forced onto the reserve base.

Another interesting case to examine is one in which it is assumed that the banking sector portfolio behavior as well as demand for money function are highly predictable so that the disturbances $u_{2}$ and $u_{3} \rightarrow 0$. In this case, real output deviations from full employment as well as unanticipated price movements are given by:

$$
\left(y-y^{*}\right)=\frac{1}{\beta(k+\delta)+\mu+\eta}\left\{(\mu+n) u_{1}+\beta \delta u_{4}\right\}
$$

and

$$
\left(p-p^{e}\right)=\frac{\delta}{\beta(\kappa+\delta)+\mu+n}\left\{(\mu+n) u_{1}-(\beta \kappa+\mu+n) u_{4}\right\}
$$


In this case real output fluctuations arising from Is curve shocks are damped as compared with the interest rate control case and both disturbances arising from the IS curve and aggregate supply curve have a smaller influence upon unanticipated price level movements. However, the aggregate supply curve disturbance does, in this case, affect real output fluctuations whereas, under the interest rate rule, real output is insulated from this shock.

It is clear that which of the two policies gives the smallest variance of real output from full employment and of unexpected prices depends in a quite complicated way on the variances of the shocks (and their covariances) as well as on all the parameters of the system (with the exception of $\alpha$ ). Also, however, it is clear how, despite the complexity of the general results, different schools of thought reach their own particular conclusions. Those who see real shocks ( $u_{1}$ and $u_{4}$ shocks) as the dominant source of disturbances in the aggregate economy and regard the monetary shocks $\left(u_{2}\right.$ and $\left.u_{3}\right)$ as being of relatively small magnitude naturally would want to adopt a policy which damped off the Is and aggregate supply shocks even at the expense of introducing some of the influence of the monetary shocks onto real output and unanticipated prices. In contrast, those :who see financial instability as the major source of macroeconomic disturbances naturally would be led to advocate an interest rate policy for its capacity to insulate output and unanticipated price changes from those shocks. Further, it is clear that those who worry more about unanticipated inflation than about real output fluctuations and who combine that worry with a belief that monetary shocks are of relatively small magnitude would have further reason for advocating the monetary base policy since, in that case, unanticipated price movements are unambiguously lower than in the fixed interest rate case. It would be possible to calculate the variances of the key variables under the alternative policies and also to derive, along the lines of Poole, formulas 
for optimal policies. However, this path is not followed since it requires arbitrary judgements concerning the weights on the variances of the different variables as well as displaying formulas of too general and uninformative a nature. Rather, the positive, predictive analysis presented above is now extended to deal with problems arising in the open economy.

\section{ALTERNATIVE, CONTROL REGIMES IN AN OPEN ECONOMY}

The open economy model that will be used is a fairly standard small open economy extension of that employed in the preceding section. It has a great deal in common with, the traditional Fleming (1962)-Mundell (1968) model and those found in Dornbusch (1976), Laidler (1977) and Barro (1978). The model is set out as follows:

$$
\begin{aligned}
& y=\alpha-\beta\left(r-p_{+1}^{e}+p^{e}\right)+\phi(\pi+\varepsilon-p)+u_{1} \\
& m=k y-\eta r+p+u_{2} \\
& m=b+\mu r+u_{3} \\
& y=y^{*}+\frac{1}{\delta}\left(p-p^{e}\right)+u_{4} \\
& \Delta b=\gamma \Delta f+(1-\gamma) \Delta c \\
& \Delta f=\psi(\pi+\varepsilon-p)-X y+\xi\left(x-\varepsilon_{+1}^{e}+\varepsilon-\rho\right)+u_{5}
\end{aligned}
$$

The notation is the same as that in the preceding section with the following additions: $\pi=$ world price level

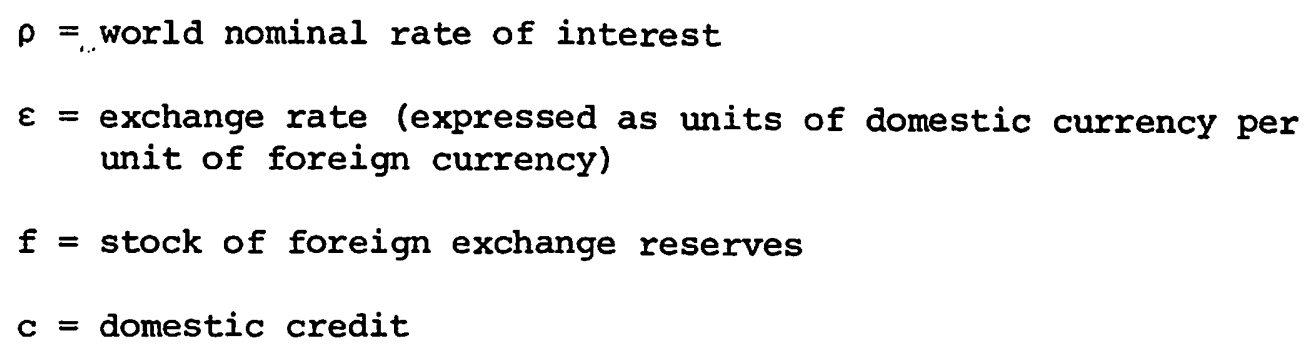




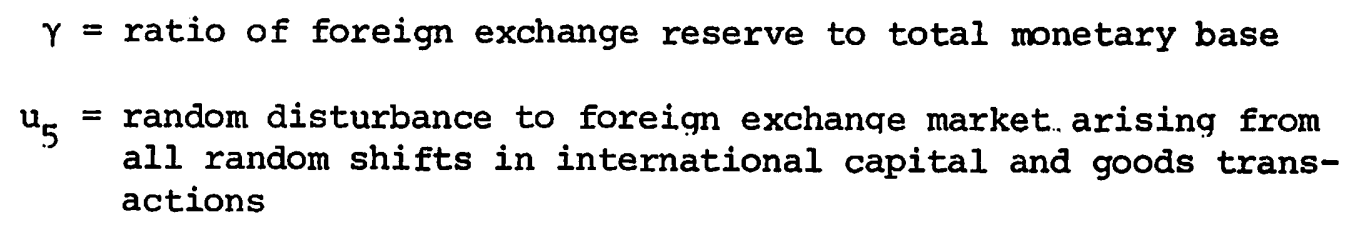
all random shifts in international capital and goods transactions

(All these additional variables, with the exception of $\gamma$, are expressed in natural logarithms.)

Equation (25) is simply an open economy aggregate expenditure function and brings in a relative international price term as affecting the allocation of domestic expenditures and foreign expenditures between domestic and foreign goods. The demand for money, supply of money, and aggregate supply functions $((26),(27)$ and $(28))$ are the same as in the preceding model. Equation (29) links the foreign exchange reserve change and the domestic credit expansion rate to the change in the unborrowed base. Strictly speaking this is an identity and $\gamma$ is a variable. However $\gamma$ will be treated as a constant in this analysis. One way of handling that would be to add a stochastic disturbance term to (29). However, this complication is ignored. The final equation simply describes the influences on the overall balance of payments arising from trade and capital account operations. The net trade balance is presumed to depend positively on the international relative price and negatively on the level of domestic output and the overall capital account balance presumed to depend on the international interest rate differential. 4 The stochastic disturbance term in this equation reflects all sources of noise arising from transactions in international markets.

The foreign rate of interest, $\rho$, and the foreign price level, $\pi$, are treated as fixed mean constant variance non autocorrelated random variables. The disturbance term $u_{5}$ is assumed to have the same properties as $u_{1}, \ldots, u_{4}$. There are many alternative policies which could be analyzed using this model. However only a limited range of alternatives will be considered. All the policies will be in the class of those designed to achieve a target for the money supply which target is believed and which becomes the 
expected money supply. The first and simplest will be that of controlling the money supply via operating on interest rates through the demand side of the money market. In addition, it will be assumed that the foreign exchange rate is fixed at a level designed to achieve a fixed expected level of the stock of foreign exchange reserves. The actual values of the unborrowed base and the stock of foreign exchange reserves will be determined by both the instrument settings and the random fluctuations hitting the economy. The second policy considered will be that of allowing the foreign exchange rate to float freely with the stock of exchange reserves set deterministically. Monetary policy will focus on the deterministic setting of the interest rate. The third policy will be the reverse of the second and will set the unborrowed base and the exchange rate deterministically letting the interest rate and stock of reserves be random. The final policy considered will be a classical freely floating exchange rate with deterministic control of the unborrowed monetary base. In this case both the exchange rate and interest rate will be determined by the various random forces hitting the economy but the monetary base and stock of foreign exchange reserves will not be allowed to be influenced by these forces.

In all cases, at the loss of some generality but at the gain of considerable simplicity, only stationary policies will be considered. Thus it will be assumed that the money stock target is a fixed value, $m^{*}$, and that the change in foreign exchange reserves desired (on the average in the case of exchange rate management) will be zero: further, the foreign price level and interest rate have fixed means.

These alternative policies are now analyzed.

(a) Managed Float with Announced Monetary Targets and Interest Rate Control

Private economic agents and the authorities all make their forecasts 
(form their expectations) by taking the expectations of the basic system (25) (30) imposing the announced policy values for the money stock as the expected money stock and an expected zero change in foreign exchange reserves. The result of this expectations operation is as follows:

$$
\begin{aligned}
y^{*} & =\alpha-\beta r+\phi\left(\pi^{e}+\varepsilon-p^{e}\right) \\
m^{*} & =\kappa y^{*}-\eta r+p^{e} \\
m^{*} & =b^{e}+\mu r \\
\Delta b^{e} & =\gamma \Delta m^{*}+(1-\gamma) \Delta c^{e}=0 \\
0 & =\psi\left(\pi^{e}+\varepsilon-p^{e}\right)-X y^{*}+\xi(r-\rho)
\end{aligned}
$$

Equations (33) and (34) determine the expected monetary base and domestic credit in a recursive manner. Equations (31), (32) and (35) constitute a simultaneous system which private agents and the authorities "solve" for the interest rate and the exchange rate to be set by policy and the expected price level which will guide both that policy setting and private agents' behavior. This simultaneous system is set out as:

$$
\left[\begin{array}{ccc}
-\beta & \phi & -\phi \\
-\eta & 0 & 1 \\
\xi & \psi & -\psi
\end{array}\right]\left[\begin{array}{l}
r \\
\varepsilon \\
p^{e}
\end{array}\right]=\left[\begin{array}{l}
y^{*}-\alpha-\phi \pi^{e} \\
m * k y^{*} \\
x y^{*}-\psi \pi^{e}+\xi \rho
\end{array}\right]
$$

and solves as:

$$
\begin{gathered}
r=\frac{1}{\beta \psi+\phi \xi}\left\{\alpha \psi+(\phi X-\psi) y^{*}+\xi \rho^{e}\right\} \\
\varepsilon=m^{*}-\pi^{e}+\frac{1}{\beta \psi+\phi \xi}\{\psi n-\xi) \alpha+[(\xi-\psi n)+(\beta+\phi n) x-\kappa(\beta \psi+\phi \xi)] y^{*} \\
\left.+(\beta+\phi n) \xi \rho^{e}\right\}
\end{gathered}
$$


: SMOTIOJ se santos ЧอṬบM

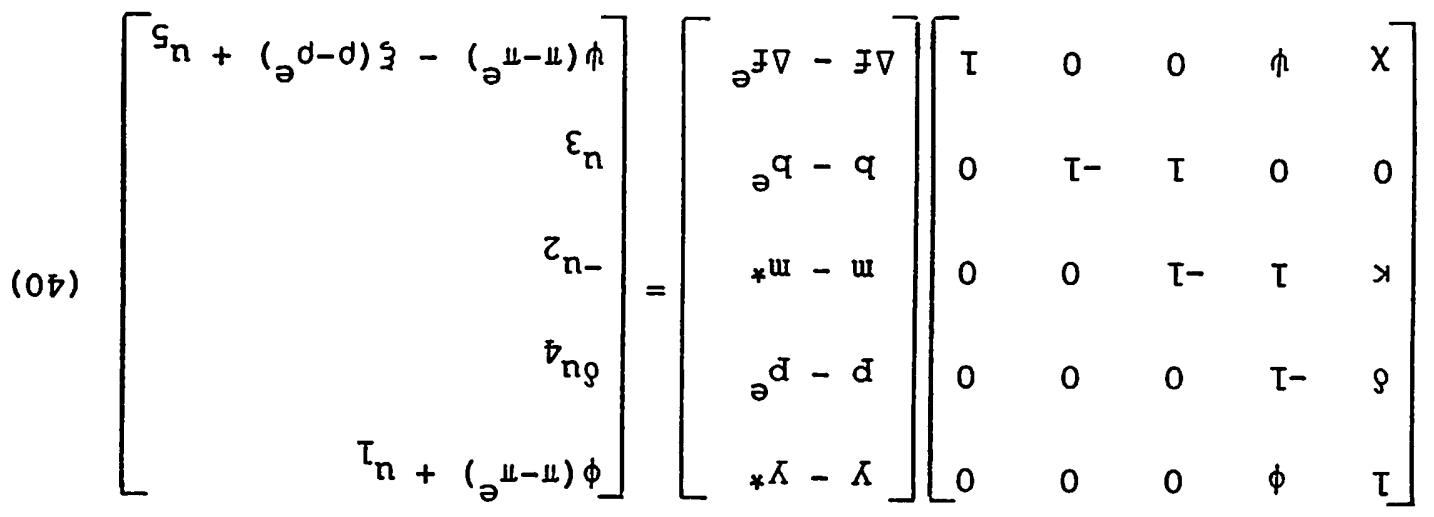

:sț uoț7exədo

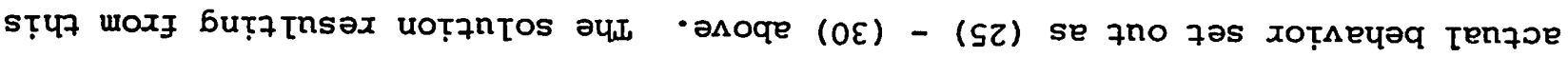

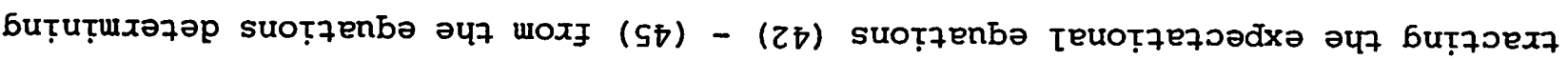

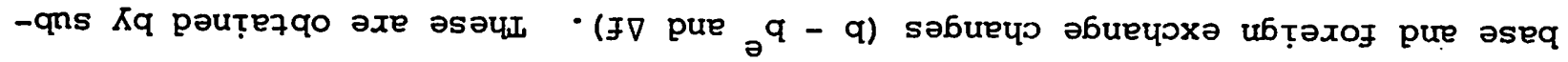

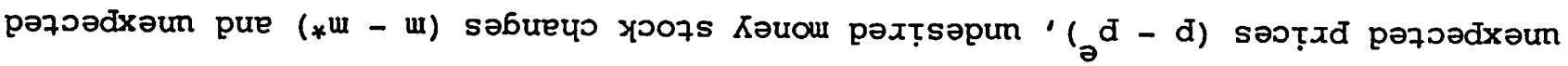

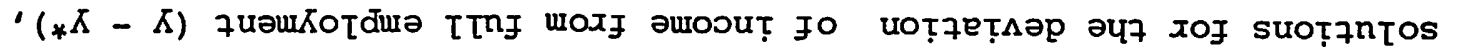

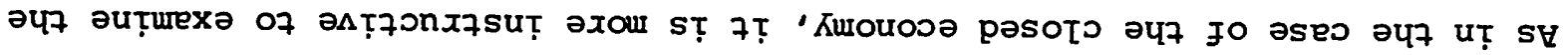

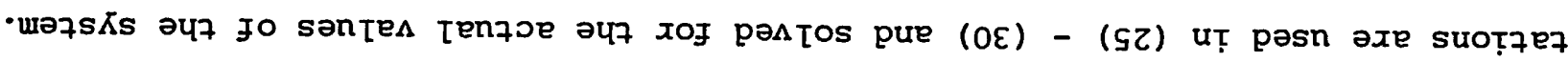

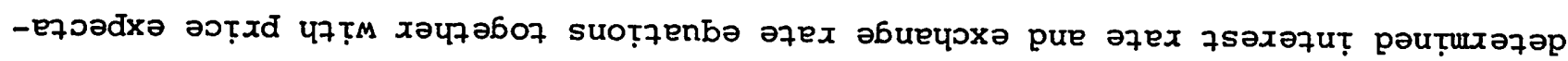

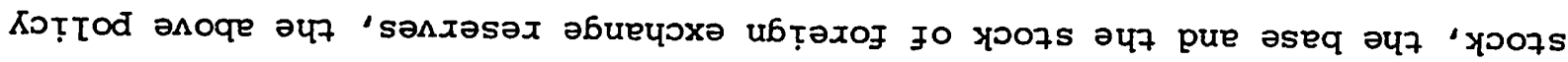

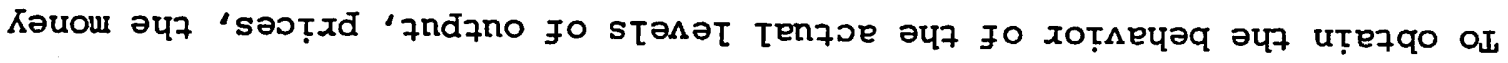

•ə7еx 7sәxә7นṬ u6т̣әxоร

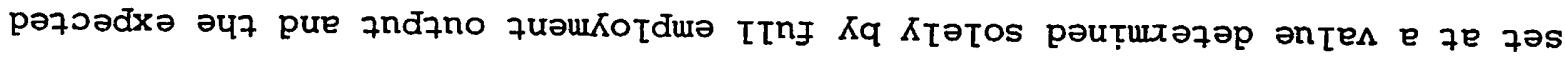

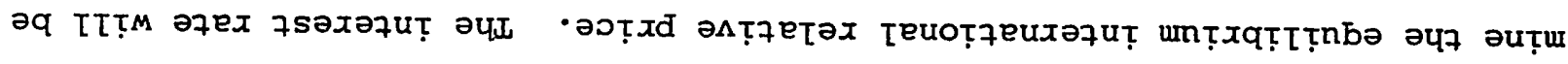

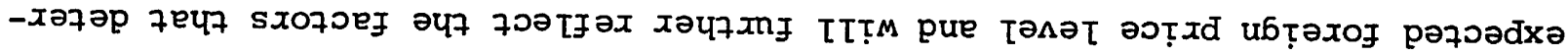

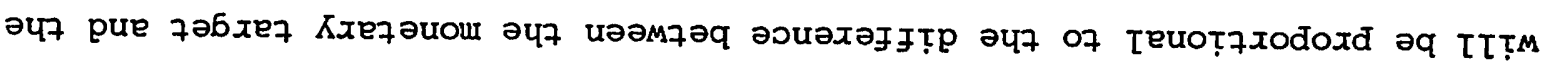

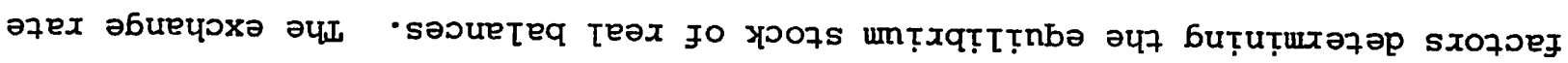

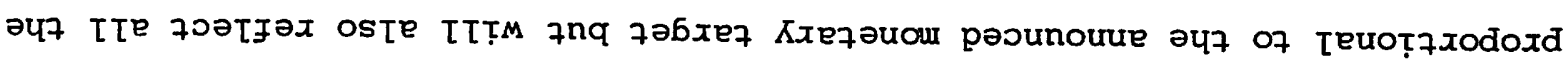

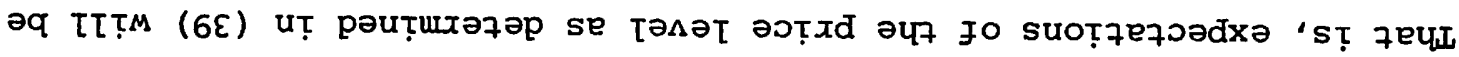

$$
\left\{\partial_{\partial} d \xi u \phi+{ }_{*} K[(\xi \phi+\phi g) x-u(\phi-\phi)]+\operatorname{vu\phi }\right\} \frac{\xi \phi+\phi g}{\mathrm{I}}+* u\left[=\theta_{\partial}^{d}\right.
$$




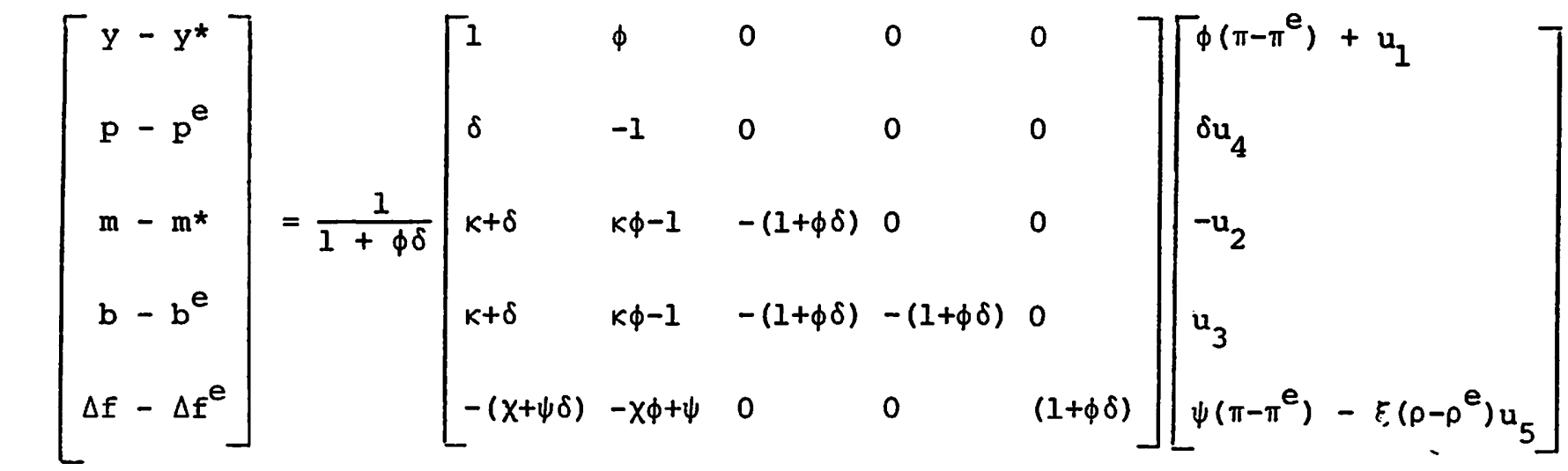

It is immediately evident that this pollcy regime generates a strong block recursive structure between the various shocks to the economy and the behavior of the endogenous variables.

Deviations of output from full employment and unexpected price level movements depend only on unexpected foreign price changes, random disturbances to aggregate expenditure and aggregate supply disturbances. These two endogenous variables are insulated completely from foreign interest rate shocks, monetary shocks, either in the demand for money function or the banking sector, and from other random disturbances arising in international markets. The money stock deviates from its target level by amounts reflecting the deviations of real output (multiplied by the income elasticity of demand) and unexpected price level movements together with random deviations in the demand for money function, $\mathrm{u}_{2}$. The monetary base reflects all the disturbances hitting the money supply and, in addition is influenced by random disturbances within the banking sector. It is the stock of foreign exchange reserves however that takes the brunt of the shocks under this regime of control. Foreign price movements, aggregate expenditure and supply disturbances, together with unexpected foreign interest rate movements and random disturbances in international markets, all come through in a powerful way in the foreign exchange reserves. The only things from which the reserves are insulated are demand for money function disturbances and banking sector portfolio adjustments $\left(u_{2}\right.$ and $\left.u_{3}\right)$. 
The degree of international capital mobility clearly has very limited impact upon the economy under this control regime. The only thing that it affects is the influence of unexpected foreign interest rate movements on the stock of foreign exchange reserves. As the parameter $\xi$ goes to zero, so this effect vanishes and as $\xi$ goes to infinity, so the effect becomes so powerful as to make the policy regime in question impossible to operate.

As in the closed economy case, the slope of the Is curve $(\beta)$ is irrelevant in generating unexpected movements of output and prices. This arises for exactly the same reason as it did in the closed economy case. In price level real output space, the aggregate demand function is vertical and shifts only as a result of unexpected foreign price movements and domestic random disturbances in aggregate expenditures.

\section{(b) Market-Determined Exchange Rate with Announced} Monetary Target and Interest Rate Control

Under this policy regime, the private agents' expectations are formed, and the authorities' forecasting is achieved by taking the expected value of the basic system of equations but setting the change in reserves equal to zero and applying the expectations operator to the exchange rate as well as to the exogenous foreign price and interest rate and domestic output and prices. This yields the following:

$$
\begin{aligned}
& y^{*}=\alpha-\beta r+\phi\left(\pi^{e}+\varepsilon^{e}-p^{e}\right) \\
& m^{*}=k y^{*}-\eta r+p^{e} \\
& m^{*}=b^{e}-\mu r \\
& 0=\psi\left(\pi^{e}+\varepsilon^{e}-p^{e}\right)-\chi y^{*}+\xi\left(r-p^{e}\right)
\end{aligned}
$$

The solutions to these equations give the authorities interest rate choice as well as private agents and the authorities' prediction about the price level and 
the exchange rate. The solution for all three of these variables is exactly the same as given in (37), (38) and (39) except that the exchange rate solution is now that for the expected rather than actual exchange rate.

The actual behavior of output, prices and the other endogenous variables is obtained by using the above equations in the basic system. Again however, rather than examine the explicit solutions, the deviations of actual from expected or target values of variables are considered. This is obtained by subtracting equation (42) from (25), (43) from (26), (44) from (27) and (45) from (30) together with equation (28) which give:

$$
\left[\begin{array}{rrrrr}
\delta & -1 & 0 & 0 & 0 \\
1 & \phi & -\phi & 0 & 0 \\
x & \psi & -(\psi+\xi) & 0 & 0 \\
\kappa & 1 & 0 & -1 & 0 \\
0 & 0 & 0 & 1 & -1
\end{array}\right]\left[\begin{array}{l}
y-y^{*} \\
p-p^{e} \\
\varepsilon-\varepsilon^{e} \\
m-m^{*} \\
b-b^{e}
\end{array}\right]=\left[\begin{array}{l}
\delta u_{4} \\
\phi\left(\pi-\pi^{e}\right)+u_{1} \\
\psi\left(\pi-\pi^{e}\right)-\xi\left(p-\rho^{e}\right)+u_{5} \\
-u_{2} \\
u_{3}
\end{array}\right]
$$

There is a strong recursivity in this system with output deviations from full employment, unexpected inflation and unexpected movements of the exchange rate all being independent of the monetary disturbances $u_{2}$ and $u_{3}$. The explicit solution to (46) is obtained by inverting the matrix on the left-hand side of (46) and is:

$$
\begin{aligned}
& =\left[\begin{array}{l}
y-y^{*} \\
p-p^{e} \\
\varepsilon-\varepsilon^{e} \\
m-m^{*} \\
b-b^{e}
\end{array}\right]=\frac{1}{D_{2}}\left[\begin{array}{lllll}
\xi \phi & (\psi+\xi) & -\phi & 0 & 0 \\
(\phi x-\psi-\xi) & \delta(\psi+\xi) & -\delta \phi & 0 & 0 \\
(-D+\psi) & x+\psi \delta & -(1+\phi \delta) & 0 & 0 \\
(-D+(K+\delta) \xi \phi) & (K+\delta)(\psi+\xi) & -(K+\delta) & -D_{2} & 0 \\
\psi\left(\pi-\pi^{e}\right)-\xi(\rho-\rho)+u_{5} & (K+\delta)(\psi+\xi) & -(K+\delta) & -D_{2} & -D_{2}
\end{array}\right]\left[\begin{array}{l}
\delta u_{4} \\
\phi\left(\pi+\pi^{e}\right)+u_{1} \\
-u_{2} \\
u_{3}
\end{array}\right] \\
& D_{2}=-\phi X+\psi+\xi(1+\phi \delta)
\end{aligned}
$$


First consider the distribution of the shocks in this case compared with the preceding managed float regime. Output fluctuations and unexpected price movements are still insulated from the monetary shocks $\left(u_{2}\right.$ and $\left.u_{3}\right)$. However, they are now affected both by the international shock, $u_{5}$, and by unexpected movements in the foreign rate of interest $\left(\rho-\rho^{e}\right)$. (A detailed comparison of the relative magnitudes of the coefficients relating the aggregate supply and aggregate expenditure shocks to output deviations and unexpected price changes is presented in a subsequent section.) The exchange rate is influenced by exactly the same forces as influence output and prices, and it too is insulated from domestic demand for money function and banking portfolio disturbances with the base taking a non-zero share of all the sources of shock.

As in the preceding case, the interest slope of the IS curve, $B$, and the interest slope of the demand for money function, $n$, do not affect these multipliers. The reason is straightforward. As before, in $p, y$ space the aggregate demand function is vertical. This means that whatever shocks occur which have an effect on aggregate output arise from shifts in that vertical function. There are in this case more things that can shift the function but there is no damping of the effects of the shocks arising from induced interest rate adjustments and thereby interest-induced spending changes. Similarly, the parameter $\eta$ does not affect the solutions since its effects come through solely on the chosen interest rate given the desired stock of money.

Detailed examination of the system set out in (47) above and the detailed comparison of it with the multipliers relating to the managed float fixed interest rate case would be extremely laborious. However, some limited comparisons are worthwhile based on alternative simplifying assumptions 
concerning some of the key paramters. One such parameter is $\xi$, the degree of capital mobility. First consider the case of perfect capital mobility in which $\xi \rightarrow \infty$. In this case the system becomes:

$$
\left[\begin{array}{l}
\mathrm{y}-\mathrm{y}^{*} \\
\mathrm{p}-\mathrm{p}^{\mathrm{e}} \\
\varepsilon-\varepsilon^{\mathrm{e}} \\
\mathrm{m}-\mathrm{m}^{*} \\
\mathrm{~b}-\mathrm{b}^{\mathrm{e}}
\end{array}\right]=\frac{1}{1+\phi \delta}\left[\begin{array}{lllll}
\phi & 1 & 0 & 0 & 0 \\
\delta \phi & \delta & 0 & 0 & 0 \\
0 & 0 & (1+\phi \delta) & 0 & 0 \\
(k+\delta) \phi & (k+\delta) & -(k+\delta) & -(1+\phi \delta) & 0 \\
(k+\delta) \phi & (k+\delta) & -(k+\delta) & -(1+\phi \delta) & -(1+\phi \delta)
\end{array}\right]\left[\begin{array}{l}
\delta u_{4} \\
\phi\left(\pi-\pi^{e}\right)+u_{1} \\
-\left(\rho-\rho^{e}\right) \\
-u_{2} \\
u_{3}
\end{array}\right]
$$

Now, as in the managed float case, output deviations and unexpected price movements depend only on aggregate supply and aggregate expenditure function disturbances. Further, the coefficients on these disturbances are exactly the same as in the managed float case. Thus, for these two variables, a market-determined exchange rate with perfect capital mobility is equivalent to a managed float with any degree of capital mobility. There are of course differences in other parts of the system. Perfect capital mobility with freely floating rates results in a full one-for-one adjustment of the exchange rate to a change in the foreign interest rate. A cet. par. rise in the foreign interest rate will cut the spot exchange rate (lead to an appreciation) in order to maintain continuous interest rate parity.

The other extreme case that is interesting to examine is that of zero capital mobility, which is captured by letting $\xi \rightarrow 0$. This yields the system set out as: 
$\left[\begin{array}{l}y-y^{*} \\ p-p^{e} \\ m-\varepsilon^{*} \\ b-b^{e}\end{array}\right]=\frac{1}{\psi-\phi x}\left[\begin{array}{lllll}0 & \psi & -\phi & 0 & 0 \\ -\psi+\phi x & \delta \psi & -\delta \phi & 0 & 0 \\ -\psi+\phi x & x+\psi \delta & 1+\phi \delta & 0 & 0 \\ -\psi+\phi x & (k+\delta) \psi & -(k+\delta) & -\psi+\phi x & 0 \\ -\psi+\phi x & (k+\delta) \psi & -(k+\delta) & -\psi+\phi x & -\psi+\phi x\end{array}\right]\left[\begin{array}{l}\delta u_{4} \\ \phi\left(\pi-\pi^{e}\right)+u_{1} \\ \psi\left(\pi-\pi^{e}\right)+u_{5} \\ -u_{2} \\ u_{3}\end{array}\right]$

In this case output fluctuations depend only on the aggregate expenditure and international disturbances, $u_{1}$ and $u_{5}$, together with unexpected foreign price movements. Unexpected price changes and unexpected exchange rate movements also depend only on these three factors. Further, in this case, unexpected movements in foreign interest rates, for rather obvious reasons, have no effect on the domestic economy at all. Naturally, both in this case and the preceding special case of perfect capital mobility, domestic money stock and banking sector portfolio shocks have no effect on output, prices and the exchange rate.

In principle it is of interest to examine in detail how each of the parameters of the model affect the relationship between the shocks and the domestic endogenous variables. However, rather than examine the full taxonomy, just one further parameter will be focussed on. This is the degree of responsiveness of domestic demand to international relative price changes, the parameter $\phi$. It is easiest to examine its role in the perfect capital mobility case considered above. Assuming perfect capital mobility, i.e., that $\xi+\infty$, the output deviations from full employment and unexpected price movements are given as follows:

$$
\begin{aligned}
& y-y^{*}=\frac{\delta \phi}{1+\delta \phi} u_{4}+\frac{\phi}{1+\delta \phi}\left(\pi-\pi^{e}\right)+\frac{1}{1+\delta \phi} u_{1} \\
& p-p^{e}=\frac{\delta^{2} \phi}{1+\delta \phi} u_{4}+\frac{\delta \phi}{1+\delta \phi}\left(\pi-\pi^{e}\right)+\frac{\delta}{1+\delta \phi} u_{1}
\end{aligned}
$$


Clearly as $\phi$ increases, so the aggregate expenditure shock $u_{1}$ has a smaller effect on prices and output. Further, it is clear that the smaller is $\phi$, the smaller are the effects of the other two aggregate supply and unexpected foreign price shocks. As $\phi+0$, so the effects of both of these shocks approach their upper bounds. In the other special case of zero capital mobility, as well as the general capital mobility case, the effects of varying $\phi$ become indeterminate since the ratio of $\phi$ and $\psi$ appear in the resulting multipliers and may not be permitted to take the same limiting values as each other.

Clearly other features of this result could be examined in detail. However, further discussion of this case will be deferred until after the next two policies have been examined.

(c) Managed Exchange Rate with Monetary Target Achieved by Base Control

Under this policy regime, the authorities announce their policy as one of setting the unborrowed base to achieve an expected money stock of $\mathrm{m}^{*}$ and setting the exchange rate to achieve a zero expected change in foreign exchange reserves. In order to make their base and exchange rate settings, the authorities take the expectations of equations (25) - (30), imposing $\Delta \mathrm{f}=0$ and $\mathrm{m}=\mathrm{m}^{*}$. Using the fact that $\mathrm{y}^{\mathrm{e}}=\mathrm{y}^{*}$, this yields:

$$
\begin{aligned}
& \mathrm{y}^{*}=\alpha-\beta r^{e}+\phi\left(\pi^{e}+\varepsilon-p^{e}\right) \\
& m^{*}=\kappa y^{*}-\eta r^{e}+p^{e} \\
& m^{*}=b+\mu r^{e} \\
& 0=\psi\left(\pi^{e}+\varepsilon-p^{e}\right)-X y^{*}+\xi\left(r^{e}-p^{e}\right)
\end{aligned}
$$

These equations are solved by the authorities for their forecasts, $p^{e}, r^{e}$, and for their instrument settings, $b$ and $\varepsilon$. Given these solutions and instrument 
settings, the behavior of the actual values of the variables (expressed as derivations from their target or expected values) are obtained by subtracting (52) from (25), (53) from (26), (54) from (27), (55) from (30) and using (28) to give:

$$
\left[\begin{array}{ccccc}
1 & \phi & 0 & \beta & 0 \\
\delta & -1 & 0 & 0 & 0 \\
\kappa & 1 & -1 & -\eta & 0 \\
0 & 0 & 1 & -\mu & 0 \\
x & \psi & 0 & -\xi & 1
\end{array}\right]\left[\begin{array}{c}
y-y^{*} \\
p-p^{e} \\
m-m^{*} \\
r-r^{e} \\
\Delta f-\Delta f^{*}
\end{array}\right]=\left[\begin{array}{c}
\phi\left(\pi-\pi^{e}\right)+u_{1} \\
\delta u_{4} \\
-u_{2} \\
u_{3} \\
\psi\left(\pi-\pi^{e}\right)-\xi\left(\rho-\rho^{e}\right)+u_{5}
\end{array}\right]
$$

the solution to which is obtained, after inverting the matrix on the lefthand side of (56) as:

$$
\begin{aligned}
& y-y^{*}=\frac{1}{D_{3}}\left[(n+\mu) u_{1}-\beta\left(u_{2}-u_{3}\right)+[(n+\mu) \phi+\beta] \delta u_{4}+(n+\mu) \phi\left(\pi-\pi^{e}\right)\right] \\
& \begin{aligned}
p-p^{e}=\frac{1}{D_{3}}\left[\delta(n+\mu) u_{1}\right. & -\delta \beta\left(u_{2}-u_{3}\right)+\left\{\delta^{2}[(n+\mu) \phi+\beta]-\delta\right\} u_{4} \\
& \left.+\delta(n+\mu) \phi\left(\pi-\pi^{e}\right)\right] \\
m-m^{*}=\frac{1}{D_{3}}\left[\mu(k+\delta) u_{1}\right. & +\mu(1+\delta \phi) u_{2}+[n(1+\delta \phi)+\beta(k+\delta)] u_{3} \\
& \left.-\mu(1-\phi k) u_{4}+\mu(k+\delta) \phi\left(\pi-\pi^{e}\right)\right]
\end{aligned} \\
& r-r^{e}=\frac{1}{D_{3}}\left[(k+\delta) u_{1}+(1+\delta \phi)\left(u_{2}-u_{3}\right)-(1-\phi k) u_{4}+(k+\delta) \phi\left(\pi-\pi^{e}\right)\right]
\end{aligned}
$$

$$
\begin{aligned}
\Delta f=\frac{1}{D_{3}}[[\xi(\kappa+\delta) & -(\eta+\mu)(x+\psi \delta)] u_{1}+[\xi(1+\delta \phi)+\beta(x+\psi \delta)]\left(u_{2}-u_{3}\right) \\
& +[\xi(\phi k-1)-\beta(x-\psi k)+(\psi-\chi \phi)(n+\mu)] \delta u_{4}+D_{3} u_{5} \\
& \left.+[(\phi \xi+\psi \beta)(\kappa+\delta)-(x-\psi)(n+\mu)]\left(\pi-\pi^{e}\right)-D_{3}\left(\rho-\rho^{e}\right)\right]
\end{aligned}
$$


where

$$
D_{3}=(1+\delta \phi)(\mu+\eta)+B(\kappa+\delta)
$$

As equations (57) to (61) indicate, all the variables in the system, with the exception of the foreign exchange reserves, are insulated from unexpected movements in foreign interest rates and the random disturbance to the overall balance of payments, $u_{5}$. However, all the remaining shocks, $u_{1}, \ldots, u_{4}$, as well as unexpected foreign price movements, affect output, prices, the money stock and interest rates. The distribution of these shocks across the variables, whilst quite complicated, has some general and simple patterns. The smaller are the interest elasticities in the monetary sector, $\eta$ and $\mu$, the more damped will be the Is curve shock, $u_{1}$, on real output and prices and the more important will be the monetary $\left(u_{2}\right.$ and $\left.u_{3}\right)$ shocks on those two variables. The Is curve slope parameter, $\beta$, has a symmetrical effect to the monetary sector interest elasticities. The steeper is the IS curve (the smaller is B) the bigger the effects of the IS curve shock on output and prices and the smaller the effect of the monetary shocks. Unexpected foreign price changes affect output and the domestic price level in a manner analogous to the domestic IS curve shock but multiplied by the parameter $\phi$ which translates an unexpected foreign price change into a change in aggregate demand. It is evident that all the shocks are concentrated on to the foreign exchange reserves. This of course is a natural and necessary consequence of pegging the exchange rate. In addition to the disturbances which affect domestic output and prices, the foreign disturbance $u_{5}$ as well as unexpected foreign interest rate movements all come through to affect the exchange reserves. Further, the degree of capital mobility is of critical importance here. The determinant $D_{3}$ does not include the capital mobility parameter $\xi$ but this parameter appears in profusion in the numerator of all but one of the 
multiplier expressions. As we move towards perfect capital mobility $(\xi \rightarrow \infty)$, foreign exchange reserves will change by an infinite amount consequent upon either an IS curve shock, domestic monetary shock, a domestic aggregate supply curve shock, unexpected price change or a foreign interest rate change. Only the foreign shock, $u_{5}$, has an effect which is independent of the degree of capital mobility and it has a one-for-one effect on reserves.

It is clear that this policy option is not available in the face of perfect capital mobility with finite reserves. However, if the degree of capital mobility is sufficiently small and the stock of reserves sufficiently large, it would be an available policy option.

A detailed comparison of the effects of the various shocks on output and prices under this policy regime with those of the others will be presented after considering the final policy option for the open economy--that of setting the monetary base and allowing the exchange rate to be market-determined.

(d) Market-Determined Exchange Rate with Monetary Target Achieved by Base Control

In this case the authorities announce their policy as that of achieving a zero change in foreign exchange reserves and setting the monetary base at some given constant level designed to achieve a target value for the money stock of $\mathrm{m}^{*}$. In order to make the base decision, the authorities use the equations (25) - (30) to forecast the variables upon which the value of the money stock conditional on the base depends. Likewise, private agents use the basic system to generate their own expectations of the price level for implementing their aggregate supply decision.

Noting again that expected $y=y^{*}$ and taking expectations of equations (25) - (30) we have: 


$$
\begin{aligned}
& y^{*}=\alpha-\beta r^{e}+\phi\left(\pi^{e}+\varepsilon^{e}-p^{e}\right) \\
& m^{*}=k y^{*}-\eta r^{e}+p^{e} \\
& m^{*}=b+\mu r^{e} \\
& 0=\psi\left(\pi^{e}+\varepsilon^{e}-p^{e}\right)-X Y^{*}+\xi\left(r^{e}-\rho^{e}\right)
\end{aligned}
$$

The authorities solve this system to generate their forecast in order to determine $\mathrm{b}$ and the private agents solve the system for the expected price level so as to implement their aggregate supply behavior.

The behavior of the actual values of the variables (expressed as deviations from their target or expected values) is obtained by subtracting (62) from (25), (63) from (26), (64) from (27), (65) from (30) and using (28) to give:

$\left[\begin{array}{ccccc}\delta & -1 & 0 & 0 & 0 \\ -\kappa & -1 & n & 1 & 0 \\ 0 & 0 & -\mu & 1 & 0 \\ 1 & \phi & \beta & 0 & -\phi \\ x & \psi & -\xi & 0 & -(\psi+\xi)\end{array}\right]\left[\begin{array}{l}y-y^{*} \\ p-p^{e} \\ m-m^{*} \\ \varepsilon-\varepsilon^{e}\end{array}\right]=\left[\begin{array}{l}u_{4} \\ u_{2} \\ u_{3} \\ \phi\left(\pi-\pi^{e}\right)+u_{1} \\ \psi\left(\pi-\pi^{e}\right)-\xi\left(\rho-\rho^{e}\right)+u_{5}\end{array}\right]$

the solution to which is obtained by inverting the matrix on the left-hand side of (66) to give:

$$
\begin{aligned}
& y-y^{\star}=\frac{1}{D_{4}}\left[-B u_{M}+M u_{R}\right] \\
& p-p^{e}=\frac{1}{D_{4}}\left[-\delta B u_{M}+\delta M u_{R}\right]-\delta u_{4}
\end{aligned}
$$




$$
\begin{aligned}
& r-r^{e}=\frac{1}{D_{4}}\left[A u_{M}+K u_{R}\right] \\
& m-m^{*}=\frac{1}{D_{4}}\left[\mu A u_{M}+\mu K u_{R}\right]+u_{3} \\
& \varepsilon-\varepsilon^{e}=\frac{1}{D_{4}}\left[T u_{1}+S u_{M}-Q u_{5}+Q(T-\psi)\left(\pi-\pi^{e}\right)+\xi Q\left(\rho-\rho^{e}\right)\right]-\delta u_{4}
\end{aligned}
$$

$$
\text { where: } \begin{aligned}
A & =-(\psi+\xi(1+\psi \delta)-\chi \phi) \\
B & =\beta(\psi+\xi)+\phi \xi \\
M & =\mu+\eta \\
K & =K+\delta \\
T & =(X+\xi \delta) M-\xi K \\
S & =(1+\delta \phi) \xi+(x+\xi \delta) B \\
Q & =(1+\delta \phi) M+\beta K \\
u_{M} & =\delta u_{4}-u_{2}+u_{3} \\
u_{R} & =(\psi+\xi) u_{1}+\xi \phi\left(\pi+\pi{ }^{e}+\rho-\rho^{e}\right)-\phi u_{5} \\
D_{4} & =-[A M-B K]
\end{aligned}
$$

Interpreting these results is not quite as straightforward as it was with the other three regimes considered. The expressions themselves are cumbersome. However there are some patterns. First it is interesting to note that the composite error defined as $u_{M}$ can be thought of as a shock to real money balances. $u_{3}-u_{2}$ is the shock to nominal balances and $\delta u_{4}$ can be thought of as a shock to the price level arising from the aggregate supply side of the economy. The composite shock defined as $u_{R}$ can be thought of as the composite of real shocks, that is, the aggregate expenditure shock, $u_{1}$ (weighted to allow 
for the fact that some of its effects are immediately damped off through the openness of the economy) together with the shocks arising from the international aspects of the economy, unexpected foreign price and interest rate movements and the overall random disturbance on the balance of payments equation. These composite shocks combine in a fairly simple way to determine the deviations of the endogenous variables from their expected or target levels. It is evident that the shocks are now distributed fully throughout the economy. All the random disturbances, together with the foreign disturbances, affect all the endogenous variables in some degree. The composite real shock affects output and prices by a weight which is proportional to the sum of the semi-elasticities of the demand for and supply of money $(\mu+\eta)$. Thus, although the monetary shocks summarized in $u_{M}$ now affect real output and prices with a positive weight (as contrasted with a zero weight in the two preceding cases) the effects of the real shocks which, in the two preceding cases also hit output and prices, have their effects modified by these monetary elasticities.

It will not be attempted to go through a detailed assessment of all these results. Rather, because of the additional insight gained, the alternative policy regimes will be explicitly compared in order to assess the different ways in which the random shocks distribute themselves throughout the economy under the alternative regimes.

(e) A Comparison of the Distribution of Shocks Under the Alternative Policies

It would be space consuming to compare the effects of all the shocks on all the endogenous variables under all the policies. Rather than do that, attention is going to be focussed on the two central macroeconomic variables, deviations of output from full employment $\left(y-y^{*}\right)$ and unexpected price level 


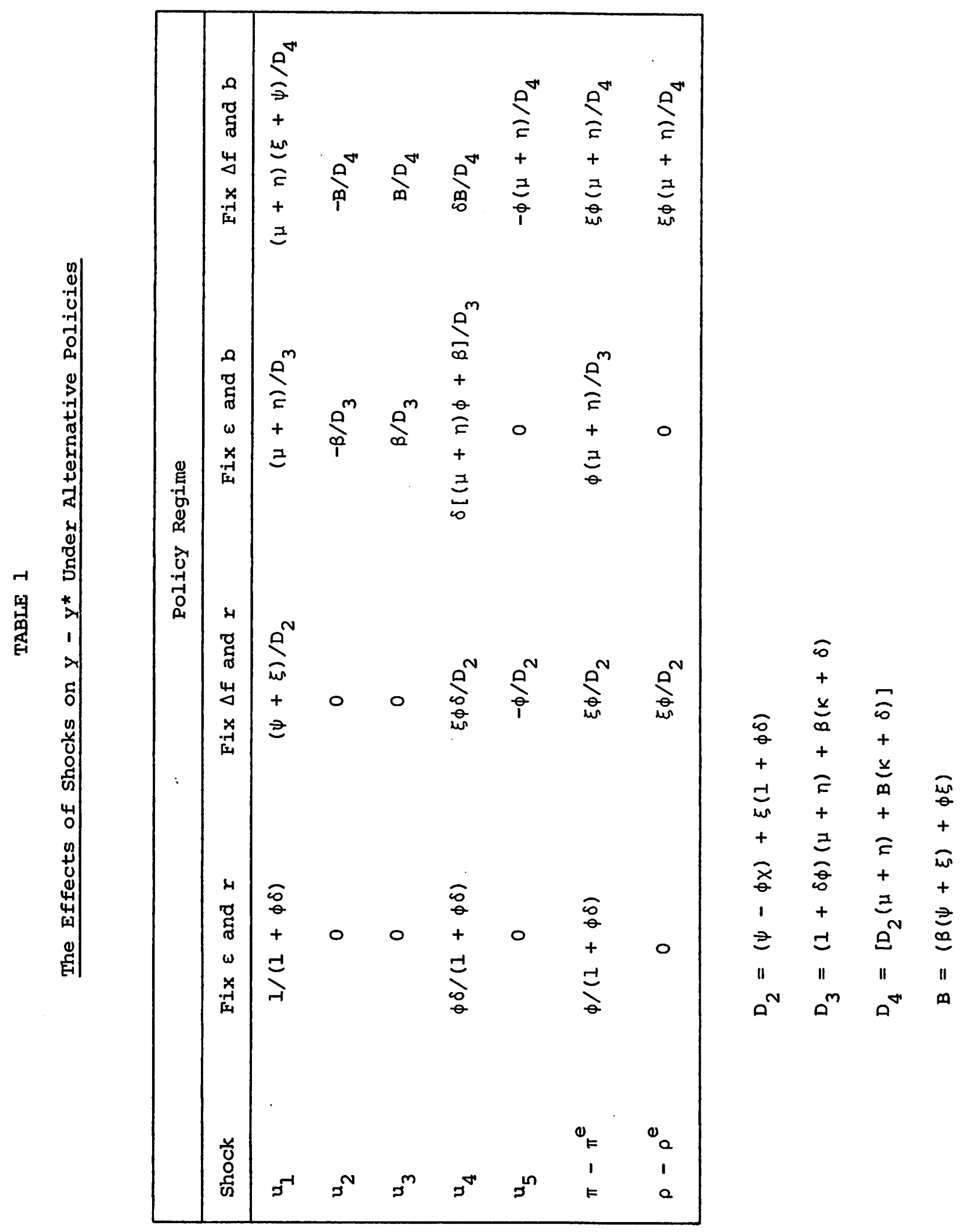


TABLE 2

Rankings of Effects of Shocks on $y-y^{*}$ Under Alternative Policies

\begin{tabular}{|c|c|c|c|c|}
\hline & \multicolumn{4}{|c|}{ Policy Regime } \\
\hline Shock & Fix $\varepsilon$ and $r$ & Fix $\Delta f$ and $r$ & Fix $\varepsilon$ and $b$ & Fix $\Delta f$ and $b$ \\
\hline$u_{1}$ & 3 & 4 & $2^{a}$ & $1^{a}$ \\
\hline$u_{2}$ & 1 & 1 & 3 & 4 \\
\hline$u_{3}$ & 1 & 1 & 3 & 4 \\
\hline$u_{4}$ & $4^{c, d}$ & $3^{c, e}$ & $2^{b, d, e}$ & $1^{b}$ \\
\hline$u_{5}$ & 1 & 4 & 1 & 3 \\
\hline$\pi-\pi^{e}$ & 4 & $3^{f}$ & $2^{f}$ & 1 \\
\hline$\rho-\rho^{e}$ & 1 & 4 & 1 & 3 \\
\hline
\end{tabular}

a if $\xi>[\phi(\delta \psi+\chi)(\mu+\eta)+\beta(1-\psi)(\kappa+\delta)] /(\beta+\phi)(\kappa+\delta)$

$b$ if $\phi K+\beta \phi+\beta \delta+(\mu+n)(I+\phi \delta)>1$

$c$ if $\psi-\phi x>0$

$d$ if $\phi k>1$

e if $\xi>[(\psi-\phi X)((\mu+\eta) \phi+\beta)] / \beta(\kappa \phi-1)$

fif $\xi>[(\psi-\phi \chi)(\mu+n)] / \beta(\kappa+\delta)$ 
movements $\left(p-p^{e}\right)$. Tables 1 and 2 summarize and rank (in some cases conditionally) the effects of the different shocks on $y-y^{*}$ under the alternative policy regimes.

It is convenient to examine these tables row by row. First consider the IS curve shock $u_{1}$. Assuming the degree of capital mobility to be sufficient (condition (a) at the foot of Table 2), the ranking of the policies (in terms of the minimization of the effect of the shock on $y-y^{*}$ ) is as indicated in the first row of Table 2. Consider first the comparison of the two fixed interest rate cases (the first two columns). The effect of a $u_{1}$ shock on output is smaller with a fixed exchange rate and fixed interest rate than with a flexible exchange rate and fixed interest rate. The intuition behind this result is straightforward. A positive $u_{1}$ shock leads to upward pressure on income and the price level and, therefore, downward pressure on the stock of foreign exchange reserves. Under a flexible exchange rate regime this leads to a depreciation of the currency (a rise in $\varepsilon$ ) which, multiplied by $\phi$, enhances the original $u_{1}$ disturbance on $y$. Under a fixed exchange rate this enhancing effect, through an induced exchange rate movement, does not occur. This is comparable to the result derived by Mundell (1961) for the effects of fiscal policy. One could imagine the $u_{1}$ shock as an unanticipated rise in government spending or tax cut to draw the parallel between Mundell's original analysis.

The effects of the $u_{1}$ shock on output with a fixed monetary base and flexible interest rate are lower under either exchange rate regime than those arising with a fixed interest rate. The key reason for this is of course that as the $u_{1}$ shock has an impact effect of raising income, the rise in income (and the induced rise in prices) lead to an increase in the demand for money and therefore a rise in the rate of interest. The interest rate increase has the effect of dampening off the initial expenditure and income 
increase. If the exchange rate is flexible (along with a fixed monetary base), then the rise in income, the rise in the price level and the rise in the rate of interest feed through to affect the exchange rate. The precise way in which the exchange rate is influenced depends upon the degree of capital mobility. There is a critical degree of capital mobility at which the depreciating effects of rising prices and income and the appreciating effects of a rise in the domestic interest rate will just offset each other, leading to no movement in the exchange rate. In this intermediate case, the fixed and flexible rates will give rise to exactly the same multiplier effect of a $u_{1}$ shock on real output. However, if capital is more mobile than that critical amount, then the appreciating effect of the interest rate will dominate and there will be a fall in $\varepsilon$ (appreciation of the currency) which gives rise to an even larger fall in international relative prices than under the fixed exchange rate case which further damps off the effect of the $u_{1}$ shock.

The two money market shocks, $u_{2}$ and $u_{3}$, have identical but opposite sign effects on real output. Under the fixed interest rate rule, whether the exchange rate is fixed or flexible, these shocks have no effect on output. They are fully absorbed by the money supply and the monetary base. However, with a fixed base these shocks do come through to affect output and, they have a smaller effect with a fixed exchange rate than with a flexible rate. The reason for this difference is that, a negative $u_{2}$ (or positive $u_{3}$ ) shock would lead to a fall in interest rates and an induced rise in income and the price level. With a flexible exchange rate, the fall in the domestic interest rate, as well as output and price rise, lead to a depreciation of the currency (rise in $\varepsilon$ ) thereby enhancing the balance of payments induced effect on aggregate demand. Thus, under the flexible rate, there is a bigger overall effect on aggregate demand arising from a monetary disturbance. 
The effect of a domestic aggregate supply shock, $u_{4}$, is somewhat complicated and can only be ranked if a series of conditions are specified. These are set out as conditions (b, $c, d$ and e) at the foot of Table 2. The ranks have been specified as shown in Table 2 on the presumption that the condition would in general be met. The conditions refer to pairwise rankings as indicated by the superscripts in the table. Comparing first the fixed exchange rate cases (columns 1 and 3), provided condition (d) is satisfied, the fixed base case dominates the pegged interest rate case. The reason for this is that, since a $u_{4}$ shock (assumed positive) raises income and lowers the price level, there is an ambiguous effect on the excess demand for money. If the income elasticity of the demand for money $(k)$ is equal to unity, then there is no impact effect on the excess demand for money and therefore no induced interest rate change. However, the fall in the price level induces a further rise in income of $\phi$ times the price level fall. This therefore would lead to an excess demand for money. However, provided the product $\phi K$ is equal to unity, the induced rise in income generates an increase in the demand for money exactly equal to the fall in the demand for money resulting from the fall in the price level. Therefore, if $\phi K$ equals one, the fixed base and pegged interest rate cases are identical. In the case where $\phi k$ is greater than one, the increase in the demand for money induced by the rise in income exceeds the drop in the demand for money induced by the fall in the price level and, the excess demand for money would, under a fixed monetary base rule, induce a rise in the interest rate and thereby damp off some of the initial expenditure increase. Thus, provided the condition $\phi \kappa>1$ is satisfied, a fixed monetary base and flexible interest rate gives most insulation from a domestic aggregate supply shock.

Next compare the flexible exchange rate cases. Here the fixed base market-determined interest rate case more easily dominates the pegged interest 
rate case since, the induced rise in the interest rate will also give rise to an appreciation of the currency (lower $\varepsilon$ ) which will produce a bigger damping effect on domestic aggregate demand through the balance of payments than would be the case with a fixed exchange rate.

The random disturbances to the balance of payments $\left(u_{5}\right)$ are of course completely insulated from real output under the two fixed exchange rate cases. With flexible exchange rates some of these effects come through via their effect on the exchange rate to influence real output. However the effect is smaller with a fixed monetary base than with a pegged interest rate. The reason for this is simply that, a (say) positive $u_{5}$ shock gives rise to an appreciation of the exchange rate (a fall in $\varepsilon$ ) which, under a pegged interest rate policy, can get no additional help from the interest rate. The appreciation of the currency will lower net foreign demand for domestic output, thereby producing a fall in real output. In the case where the interest rate is market determined however, some of the effects of a positive $u_{5}$ shock will fall on a depression of the domestic interest rate which will induce some rise in output to partly offset the output depressing effects of the appreciation of the currency.

Unexpected foreign price changes have their smallest effect on domestic real output with a fixed monetary base and flexible exchange rate. They have their maximal effect with a fixed interest rate and pegged exchange rate. A comparison of the two intermediate cases turns on the degree of capital mobility. The reason for the ordering of the two extreme cases is that an unexpected rise in foreign prices with both pegged interest and exchange rates gets no damping from either of those two sources. However, with market-determined exchange rates and interest rates, the rise in the foreign price level will in part give rise to an appreciation of the currency (fall in $\varepsilon$ ) thereby to some degree damping off the effect on domestic demand of that foreign price shock. 
Further, there will be an induced rise in domestic interest rates which also has an expenditure and output dampening effect. In the two intermediate cases, either the exchange rate or the domestic interest rate is permitted to do some damping and, the one which has the biggest effect depends on how fast domestic interest rates are induced to move which in turn depends on the degree of capital mobility in a fairly straightforward and obvious way. Finally, the effects of unexpected foreign interest rate movements are insulated from domestic output under fixed exchange rates, their full effect coming through onto the stock of foreign exchange reserves. With flexible exchange rates, a fixed monetary base produces a smaller shock to domestic real output than does a pegged domestic exchange rate. The damping effect of foreign interest rate shocks is identical to that of overall balance of payments $\left(u_{5}\right)$.

An examination of the effects of these alternative shocks on unexpected domestic price level movements is very similar to the analysis concerning real output fluctuations in all cases except for a $u_{4}$ aggregate supply shock. In all these other cases, the various shocks can be viewed as affecting the position of the aggregate demand function. Anything which shifts the aggregate demand function is going to change both unexpected output and unanticipated prices in the same direction and linked by the slope of the aggregate supply function, $\delta$. Thus, the entire discussion above concerning the effects of shocks under the alternative policy regimes on real output apply to price movements. The one exception is the $u_{4}$ aggregate supply shock which, unlike the others, shifts the aggregate supply function. The ranking of the effects of this shock on prices necessarily is the opposite of its ranking on output. Thus, the regime which best insulates unexpected domestic price changes from an aggregate supply shock is that of fixed exchange and fixed interest rates. The 
one which gives rise to the biggest effect is the pegged base and flexible exchange rate.

simply counting the number of cases in which a policy takes first rank in the minimization of the effects of shocks on output and unexpected price movements would make policy one, the fixed exchange rate/fixed interest rate policy look good. It takes first place for both the domestic monetary shocks, the foreign interest rate shock and the foreign random disturbance $u_{5}$. It also dominates in the effects that it permits aggregate supply shocks to have on unexpected price movements but is worst in terms of the effects of aggregate supply shocks on real output and of unexpected foreign price changes on both prices and output. The policy of fixing the interest rate and the stock of reserves, permitting the exchange rate to be freely floating, looks very bad. It takes fourth place in the effects that it permits aggregate expenditure shocks $\left(u_{1}\right)$ and foreign random shocks and foreign interest rate changes $\left(u_{5}\right.$ and $\left.\rho\right)$ and also it only ranks third in the effects that it permits to feed through from unexpected foreign price changes and aggregate supply shocks. It shares first place with policy one in fuliy insulating output and prices from domestic monetary $\left(u_{1}, u_{2}\right)$ shocks. This policy is then, apart from a reversal of ranking on unexpected foreign prices, very solidly dominated by policy one.

Superficially, from counting their number of first and second places in the rankings, the fixed base policies do not look good. They are the only policies which permit domestic monetary shocks to hit output and prices. However, they provide the best insulation from unexpected foreign price movements and the best insulation to real output though the least insulation to prices, from aggregate supply shocks. However, there is no way of avoiding aggregate supply shocks affecting both output and prices and in a way such 
that the rankings on the two variables will be reversed. Different policies have different implications for the steepness of the aggregate demand function. An aggregate supply shock which shifts the supply curve must inevitably have a bigger effect on output the smaller its effect on prices. Thus, in the absence of a procedure for deciding whether to place primary emphasis on unexpected price movements or output deviations, it is not possible to rank policies on the criterion of the insulation they give from this source of shock.

Choosing between the alternative policies really boils down to the empirical matter of assessing the relative magnitudes of the domestic and monetary real shocks and the foreign shocks and the magnitudes of a relatively small number of key parameters. If the domestic monetary shocks $\left(u_{2}\right.$ and $\left.u_{3}\right)$ are relatively small, then the fact that fixed base policies rank first with regard to the effects of these shocks on both output and prices may not be a serious matter since in any event the multiplier on these shocks is unambiguously less than one. Further, if the shocks arising in the domestic real sector $\left(u_{1}\right.$ and $u_{4}$ ) as well as unexpected foreign price movements, are the dominant sources of shock, then this is further reason to favor the fixed base policies. The fixed base policies would be further favored if the interest parameters in the monetary sector $(\mu$ and $\eta$ ) are relatively small since the multipliers on the foreign shocks as well as the domestic Is curve shock are all proportional to the sum of those elasticities. It appears from the detailed comparisons of the alternative policies that a key matter which would influence the choice of the alternatives is the principal source of shock. If the principal shocks are domestic Is curve, domestic aggregate supply curve as well as unexpected foreign price changes, then the favored policy would be a fixed monetary base with a flexible exchange rate. If alternatively, domestic and foreign monetary shocks $\left(u_{2}, u_{3}, u_{5}\right.$ and 
$\rho-\rho^{e}$ ) are the dominant ones, then the other extreme policy of a fixed exchange rate and fixed interest rate is indicated. The two intermediate policies seem to be dominated by these two extreme ones.

\section{CONCLUSIONS}

The main conclusions which emerge from this paper are straightforward. First, introducing rational expectations into a standard macroeconomic model whilst making the assumption that the exogenous variables are stationary random processes free from autocorrelation, produces an analysis of unexpected exogenous variable changes which are very well-known and are exactly the same as the usual predictions concerning the effects of the actual value of exogenous variable changes under a non-rational expectations approach. Second, the problem of policy design becomes a very different problem with rational expectations from that under some alternative, for example, adaptive expectations, procedure. In the latter case the derivation of optimal feedback rules is the appropriate way to examine policy design. In this rational expectations case, however, the problem of policy reduces to one of specifying the ways in which noise will be permitted to influence or not influence variables which could in principle be controlled exactly by the authorities. The policies are then compared by examining the effects of alternative policy regimes on the multipliers which link the endogenous variables to the various sources of shock. Thus, the basic multiplier analysis remains conventional but the interpretation of the multiplier is unconventional. In the traditional analysis the derivation of a result which showed that the multiplier effect of some exogenous variable $a$ on some endogenous variable $b$ was large, was taken to be good news and taken to indicate that by moving the variable $b$ a small way, a desired adjustment in a could be achieved. In this approach, the policy 
message is that if the system is designed in such a way as to make a multiplier from some exogenous variable to some endogenous variable large, then if that exogenous variable displays a large amount of noise that noise will come through in an amplified way in the endogenous variables which it has sought to stabilize.

Many questions remain and have not been addressed here. An obvious one is that of optimality. Policies have simply been described, analyzed and compared but in no overall sense have they been ranked. The optimality problem could be addressed but it would be fairly cumbersome. There is an additional question which might also be of some importance and interest, namely that of the frequency with which policy instrument settings should be changed. The unit of time adopted in the analysis in this paper is fixed and policy is assumed to be changed each fixed time unit. However, it may be more appropriate to work with a temporal aggregation scheme that permits policy instruments to be set for a number of time units, the number in question to be determined optimally. Both of these potential extensions are very close to the macroeconomic literature on indexation developed recently in two papers by Jo Anna Gray (1976, 1978). The basic analytical techniques used in those papers could probably be extended to handle policy optimality and optimal review frequency.

A major problem with the analysis contained in this paper for the design of actual policy is the assumption that all economic agents can distinguish between transitory and permanent changes in exogenous variables, which is implied by the assumption that the exogenous variables have fixed and known means. If that assumption is relaxed, then important additional problems arise. Its relaxation would point strongly in favor of the fixed monetary base-flexible exchange rate policy, on the grounds that setting 
an interest rate and an exchange rate at levels that were inappropriate (that is, based on false estimates of the means of the exogenous variables) would lead to cumulative movements in reserves and monetary aggregates and be associated with serious dynamic instability.

Finally, of course, there are many empirical questions. First there is a question as to the empirical relevance of the basic rational expectations approach. This is beginning to receive attention and apparently performing well (see in particular Barro, 1977). Finally, with appropriately estimated models based on a rational expectations specification together with features that can generate the appropriate amount of autoregressiveness observed in the real world economy, it would be necessary to conduct an appropriate econometric policy evaluation and comparison by examining alternative counterfactual histories in which the alternative policies examined here, together with others of relevance, could be compared recognizing however that under different policies, different expectations procedures would be employed. 


\section{FOOTNOTES}

$1_{\text {This account is based on conversations with Charles Goodhart of }}$ the Bank of England and George Freeman and Charles Freedman of the Bank of Canada. They are not responsible, however, for my interpretation.

2 For an analysis of the case in which a change has been made in the policy strategy but where private agents are not aware of this change, see Parkin (1977).

${ }^{3}$ It appears that most monetary authorities use the forecasts for $y$ and $p$ which arise from a model in which $m$ has little or even no influence on those variables. It would be of major importance to analyze the sonsequences of alternative monetary policies under rational expectations where there is lack of knowledge and consensus on the "true" model. It is conjectured that in such a case, base control will strongly dominate interest rate control.

${ }^{4}$ Although this capital account formalation is in flow terms, the experiments conducted do not suffer as a result. Explicit multi-period analysis with growth and ongoing capital movements, all ignored here, would require an explicit stock adjustment treatment of the capital account (as well, of course, as of investment and portfolio behavior). 
REFERENCES

Barro, R. J. (1977) - Unanticipated Money Growth and Unemployment in the United States, American Economic Review, 67, no. 2, March, pp. 101-115.

(1978). A Stochastic Equilibrium Model of an Open Economy Under Flexible Exchange Rates, Quarterly Journal of Economics, February, pp. 149-164.

Boyer, R. S. (1978). Optimal Foreign Exchange Market Intervention, forthcoming in Journal of Political Economy, December.

Dornbusch, R. (1976). Expectations and Exchange Rate Dynamics, Journal of Political Economy, 84, no. 3, pp. 1161-1176.

Fisher, I. (1911). The Purchasing Power of Money, New York, Macmillan.

Fleming, J. M. (1962). Domestic Financial Policies Under Fixed and Floating Exchange Rates, IMF Staff Papers, 9, pp. 368-379.

Gray, J. A. (1976). Wage Indexation: A Macroeconomic Approach, Journal of Monetary Economics, 2, no. 2, pp. 221-235.

(1978). On Indexation and Contract Length, Journal of Political

Economy, 86, no. 1, February, pp. 1-18.

Laidler, D. (1977). Expectations and the Behaviour of Prices and Output Under Flexible Exchange Rates, Economica, 44, !?ovember, pp. 327-336.

Mundell, R. A. (1969). Flexible Exchange Rates and Employment Policy, Canadian Journal of Economics and Political Science, 27, pp. 509-517; reprinted in R. A. Mundell (1968), Ch. 17.

(1968). International Economics, New York, Macmillan.

Parkin, M. (1977). The Transition from Fixed Exchange Rates to Money Supply Targets, Journal of Money, Credit and Banking, IX, no. 1, pt. 2, February, pp. 228-242. 
Poole, w. (1970). Optimal Choice of Monetary Policy Instruments in a Simple Stochastic Macro Model, Quarterly Journal of Economics, 84, May, pp. 197-216.

Sargent, T. J. and N. Wallace (1975). 'Rational' Expectations, the Optimal Monetary Instrument and the Optimal Money Supply Rule, Journal of Political Economy, April, 83, pp. 241-254. 